\title{
"El Derecho fundamental de protección de datos personales de los aspirantes a Magistrados de La Corte Suprema de Justicia de Honduras, proceso de selección 2015 - 2016"
}

The Fundamental Right of protection of personal data of the candidates for Magistrates of the Suprime Court of Justice of Honduras, selection process 2015-2016

\author{
Abog. Yolany Isabel Cambar*
}

\section{Resumen}

El presente artículo está inspirado en nuevos criterios y preceptos jurídicos, la doctrina y la jurisprudencia nacional e internacional en materia de protección de datos personales como un derecho fundamental inherente a toda persona. Asimismo, busca estudiar la regulación de un fenómeno jurídico reciente, suscitado a raíz de los inevitables avances en las tecnologías de la información y del creciente uso de las redes sociales, las que han permitido la existencia de graves violaciones al derecho a la intimidad y privacidad de las personas. En ese contexto, y tomando como referente el recién pasado proceso de selección de candidatos a magistrados de la Corte Suprema de Justicia en Honduras, se procura determinar si la Junta Nominadora en su condición de ente responsable y garante, protegió adecuadamente los datos personales de los aspirantes a magistrados durante dicho proceso, identificando asimismo, las acciones adoptadas en su tratamiento, y en definitiva determinar los vacíos jurídicos en materia de protección de datos en Honduras.

Palabras Clave: Datos personales, Habeas Data, Tratamiento, Sociedad de la Información.

\section{Abstract}

This article is inspired by new aspects and legal precepts, doctrine and national and international jurisprudence on the protection of personal data as a fundamental right inherent to every person. It also seeks to study the regulation of a recent legal phenomenon, raised as a result of the inevitable advances in information technology and the increasing use of social networks, which have allowed the existence of serious violations of the right to privacy and privacy of people. In this context and taking as reference the newly passed selection process of candidates for judges of the Supreme Court in Honduras, seeks to determine whether the Nominating Board in its capacity as responsible entity and guarantor adequately protect personal data aspiring judges during that process, also identifying the actions taken in their treatment, and ultimately determine the legal gaps in data protection in Honduras.

Key Words: Personal Data, Habeas Data, Treatment, Information Society.

Fecha de Recepción: martes 31 de mayo 2016

Fecha de Aprobación: martes 01 de noviembre 2016 


\section{Introducción}

El presente trabajo de investigación tiene como objetivo exLa protección de datos personales, no es un tema fácil de socializar en la sociedad hondureña, debido a que existe un evidente desconocimiento de los principios rectores de las nuevas tecnologías. Hoy en día, mantenerse en el anonimato con el uso excesivo de las nuevas tecnologías de la información y la comunicación, resulta imposible, y este fenómeno provoca un debilitamiento de nuestra intimidad, facilitando su transgresión por terceros en la actual sociedad de la información.

En la actualidad es cada vez más común enterarse a través de distintos medios de comunicación, de la existencia de graves violaciones a la intimidad y privacidad de las personas, las que se han incrementado a causa de los avances tecnológicos, así como del creciente uso de las redes sociales. Esto se debe a que las actividades que se desarrollan a cada instante dejan un rastro invisible a simple vista, de quiénes somos, qué hacemos, dónde estamos, cuáles son nuestros hábitos y preferencias, así como muchos otros datos, que al ser asociados por sistemas informáticos proporcionan un perfil de cada individuo.

Y es así, como la vida de las personas hoy en día gira en torno a proporcionar de manera consciente 0 inconsciente, obligatoria, voluntaria 0 involuntaria datos personales como ser: el nombre, dirección residencial, afiliación política, ideología política, creencias religiosas, números telefónicos, edad, estado civil, historial crediticio, estado de salud, entre otros. Lo anterior, es producto de diferentes actividades del diario vivir como, aperturas y cancelación de cuentas, depósitos bancarios, consultas médicas, solicitudes de información, pagos electrónicos, compras a través de Internet, entre muchas otras operaciones. En este sentido, es cierto que el Internet ha logrado facilitar las actividades diarias en el trabajo, estudios, comercio, etc.; sin embargo, también ha traído consigo graves problemas de invasión a la privacidad e intimidad, asociados principalmente al uso indebido de los datos personales y del incorrecto tratamiento por parte de quienes realizan esta actividad.

La protección de datos personales es un derecho de los llamados de tercera generación, con orígenes marcadamente europeos, y que ha tenido en las últimas tres décadas una rápida evolución, principalmente por la revolución cibernética. Este derecho garantiza a la persona un poder de control y disposición sobre sus datos personales, permitiéndoles consentir su recolección y uso, así como a saber quién los posee y con qué finalidad.

\section{Metodología}

El método utilizado en la investigación ha sido el análisis documental de la normativa nacional e internacional, relacionado con la protección de datos personales, específicamente el proceso selección de candidatos a magistrados de la Corte Suprema de Justicia 2015 - 2016, desarrollado por la Junta Nominadora.

Una vez realizado el análisis bibliográfico, se sintetizarán los aspectos más relevantes que tienen incidencia en el caso que nos ocupa, facilitando el arribo de conclusiones y recomendaciones tendientes a mejorar el sistema selección a futuro, se analizará la legislación pertinente y se harán consultas con expertos.

\section{Sipnosis}

Entre los tratados internacionales que han ayudado al desarrollo de la protección de datos en Latinoamérica, se encuentra la Declaración Universal Derechos Humanos ${ }^{1}$ del 10 de diciembre de 1948 que en su artículo 12 manifiesta que "nadie será objeto de injerencias arbitrarias en su vida privada, familiar, su domicilio o su correspondencia, ni de ataques a su honra o a su reputación." Toda persona tiene derecho a la protección de la ley contra tales injerencias o ataques. Por otro lado, se encuentra el artículo 17 del Pacto Internacional de Derechos Civiles y Políticos de $1966^{2}$, en donde se busca proteger estos derechos. Ya a nivel del Continente Americano, encontramos la Convención Americana de Derechos Humanos ${ }^{3}$ de 1969, donde en su artículo 11 se reconoce el derecho a la privacidad. El Derecho interno hondureño en la Constitución de la República de 1982 se encuentra el artículo 76 que: "garantiza el derecho al honor, a la intimidad personal, familiar y a la propia imagen".

Transcurrieron muchos años para dar el siguiente paso en cuanto a protección de datos se refiere, primero con una serie

1- Declaración Universal de los Derechos Humanos del 10 de diciembre de 1948 en Francia accesible en http://www.humanium.org/es/ddhh-textocompleto/\#

2- Artículo 17 1. Nadie será objeto de injerencias arbitrarias o ilegales en su vida privada, su familia, su domicilio o su correspondencia, ni de ataques ilegales a su honra y reputación. 2. Toda persona tiene derecho a la protección de la ley contra esas injerencias o esos ataques. PACTO INTERNACIONAL DE DERECHOS CIVILES Y POLÍTICOS Adoptado y abierto a la firma, ratificación y adhesión por la Asamblea General en su Resolución 2200 A (XXI), de 16 de diciembre de 1966 Entrada en vigor: 23 de marzo de 1976, de conformidad con el artículo 49 accesible en: http:// www.acnur.org/t3/fileadmin/scripts/doc.php?file=t3/fileadmin/Documentos/ $B D L / 2001 / 0015$

3- 7CONVENCION AMERICANA SOBRE DERECHOS HUMANOS (Pacto de San José) San José, Costa Rica 7 al 22 de noviembre de 1969 Artículo 11. Protección de la Honra y de la Dignidad. Accesible en: http://www.oas. org/dil/esp/tratados_b-32_convencion_americana_sobre_derechos_humanos.htm 
de intentos de reforma constitucional con el fin de introducir a la Constitución de la República el recurso de Hábeas Data ${ }^{4}$, y fue hasta el 23 de enero de 2013 que bajo Decreto 2372012 fueron ratificados por el Poder Legislativo los artículos relativos al Habeas Data incluidos en la Ley sobre Justicia Constitucional ${ }^{5}$ en la que manifiesta que el Habeas Data se encuentra dentro de la competencia del Poder Judicial hondureño en la Corte Suprema de Justicia, a través de la Sala de lo Constitucional.

En la Acción de Exhibición Personal y de Habeas Data, donde en su artículo numero 13 expresa que "el Habeas Data únicamente puede promoverla la persona cuyos datos personales o familiares consten en los archivos, registros públicos o privados de la siguiente manera: Toda persona tiene derecho a acceder a la información sobre si misma o sus bienes en forma expedita y no onerosa, ya esté contenida en bases de datos, registros públicos o privados y, en el caso de que fuera necesario, actualizarla, rectificarla y/o enmendarla" y previo a poder recurrir a dicha garantía se deberá agotar la vía administrativa ${ }^{6}$ ante los diferentes órganos del Estado; dicho recurso podrá ser interpuesto sin necesidad de poder ni formalidad alguna; y pueden ser presentadas verbalmente 0 por escrito, utilizando cualquier medio de comunicación, en horas o días hábiles e inhábiles y queda libre de costas.

\section{Sociedad de la información y su influencia en el Derecho}

Las sociedades son cambiantes, y van evolucionado con el paso de los años; por lo cual igual fenómeno habría de suceder con las normas que las rigen. Lo interesante e intrigante del derecho y lo que mantiene al abogado en constante estudio es tratar de indagar cómo evolucionará la norma al momento de surgir una nueva necesidad o elementos que vienen a complementar las relaciones e interacciones entre las personas.

La necesidad de proteger los datos personales de los particulares en la sociedad de la información tiene su auge en el presente siglo XXI, donde se ha observado que la tecnología ha ejercido una influencia importante en muchas de las áreas de estudio del derecho. En la actualidad, constantemente, cuando nos referimos al tema de la protección de datos, lo relacionamos con la sociedad de la información, sin embargo, no hay un concepto en concreto de la misma. Se han desa-

\footnotetext{
4- La vigente Constitución que data de 1982 en principio reconocía solamente las garantías constitucionales como el recurso de Amparo, la Inconstitucionalidad, Recurso de Revisión, y el Habeas Corpus

5- Decreto 244-2003 Ley sobre justicia Constitucional; publicada en el Diario Oficial La Gaceta No. 30,792 de fecha 3 de septiembre de 2005.

6- Artículo 40 de la LJC: "El recurso de habeas data será interpuesto ante la Sala Constitucional de la Corte Suprema de Justicia cuando se haya agotado el trámite administrativo correspondiente'.
}

rrollado varias conceptualizaciones como la presentada por TREJO DELARBRE (2001)7; en la cual describe la misma como "una época caracterizada principalmente por la apabullante diversidad de datos que es parte de la vida en la actualidad, la multilateralidad en relación a toda la información que enviamos y recibimos de todas partes"; Uno de los rasgos más sorprendentes de la sociedad de la información, es la capacidad de crear y permitir el desarrollo de una identidad digital.

Ante esta nueva realidad se hizo necesario que los países regularan el manejo de archivos, procesamiento y divulgación de información que sobre las personas constaban en registros o bases de datos de entidades públicas y privadas; todo esto con la finalidad de regular su tratamiento legítimo, controlado e informado, a efecto de garantizar la privacidad y el derecho a la autodeterminación informativa de las personas. Dentro de esta autodeterminación informática de las personas, hay que considerar que surge a partir de ciertas garantías y derechos ya regulados, como ser la intimidad y la privacidad.

\section{Legislación de la Unión Europea}

Este particular se concentra en dos instrumentos fundamentales, aunque se puede añadir algún otro, el primero es el Convenio Europeo de Derechos Humanos (CEDH) de 1950 y el segundo es el Convenio para la protección de las personas con respecto al tratamiento automatizado de datos de carácter personal de 1981 (C1981). Cabe añadir también, alguna referencia al Convenio de prevención de la tortura de 1987 (C1987). El examen de estos instrumentos nos revela que en el sistema del Consejo Europeo, el derecho a la protección de datos personales no es sino una manifestación específica del derecho al respeto de la vida privada.

EI CEDH, en su artículo 8 dispone en su apartado primero que «toda persona tiene derecho al respeto de su vida privada y familiar, de su domicilio y de su correspondencia» para añadir en el apartado segundo las condiciones en las que ese derecho se puede limitar. De acuerdo con el Convenio, el derecho al respeto de la vida privada puede ser limitado cuando se den varias circunstancias. En primer lugar, que la limitación esté «prevista en la ley»; en segundo lugar, que la misma sea «necesaria» en una "sociedad democrática»; y, en tercer lugar, que pretenda proteger una serie de bienes y derechos («la seguridad nacional, la seguridad pública, el bienestar económico del país, la defensa del orden y la prevención del delito, la protección de la salud o de la moral, o la protección de los derechos y las libertades de los demás») ${ }^{8}$.

7- TREJO DELARBRE, RAUL (2001) Vivir en la Sociedad de la Información; Orden global y dimensiones locales en el universo digital, Revista Iberoamericana de Ciencia y Tecnología, Sociedad e Innovación, Número 1 / Septiembre - diciembre 2001

8- Sobre el derecho del art. 8 CEDH véase mi libro El derecho a la protec- 


\section{Desarrollo jurisprudencial.}

Estrasburgo: Fue mucho más lejos de lo que previeron los demás órganos del Consejo de Europa, así se desprende de los dos principios básicos que ha establecido en esta materia. En primer lugar, que la protección de datos personales forma parte del derecho al respeto de la vida privada (desautorizando así al Comité de Ministros que dio la respuesta contraria a la Asamblea Consultiva) y, en segundo lugar, que, en la regulación de ese derecho, los Estados gozan de un amplio margen de apreciación.

En primer lugar, de forma constante, el $\mathrm{TEDH}^{9}$ ha interpretado el derecho al respeto de la vida privada en un sentido $a^{2} p_{1 i}{ }^{10}$. Según el TEDH «esta interpretación amplia se corresponde con la del Convenio del Consejo de Europa del 28 de febrero de 1981 para la protección de los individuos respecto al tratamiento automatizado de datos personales que entró en vigor el 1 de octubre de 1985, cuyo propósito es 'asegurar en el territorio de cada parte a todos los individuos... respeto para sus derechos y libertades fundamentales y en particular su derecho a la intimidad respecto al tratamiento automatizado de datos personales que le afecten', quedando definidos tales datos personales como 'cualquier información relativa a un individuo identificado o identificable'» ${ }^{11}$

El mismo tribunal ha establecido que en las cuestiones relativas al acceso por el público a datos personales, las autoridades nacionales gozan de un «margen de apreciación» para sopesar el alcance de la reserva de los datos personales, que depende de diversos factores, como la naturaleza o entidad de los intereses en juego y la gravedad de la interferencia. ${ }^{12}$

\section{Doctrina del Derecho a la protección de datos personales.}

Los datos de alguien son personales y tiene el derecho a la reserva y confidencialidad o a la cobertura mayor de la

ción de la vida privada en la jurisprudencia del Tribunal Europeo de Derechos Humanos, Civitas, Madrid, 1994. La cuestión de los límites se halla desarrollada en pp. 84-121.

9- STEDH A 116 Leander v. Suecia, de 26 de marzo de 1987 (1987) 9 E.H.R.R. 433 (n. ${ }^{\circ} 48$, p. 450).

10- Ya la STEDH A 251-B Niemitz v. Alemania, de (1993) 16 E.H.R.R. 97 (n. $\left.{ }^{\circ} 56, p .106\right)$ reconocía que el derecho al respeto de la vida privada y del domicilio abarcaba actividades profesionales o comerciales. También es interesante la interpretación amplia que ofrece la STEDH Friedl v. Austria, de 31 de enero de 1995 (1996) 21 E.H.R.R. 83 (n. ${ }^{\circ} 44$, p. 87 ).

11- STEDH Amann v. Suiza, de 16 de febrero de 2000, (2000) 30 E.H.R.R $843\left(n .^{\circ} 65\right.$, p. 871)

12- STEDH Z v. Finlandia, de 25 de febrero de 1997, (1998) 25 E.H.R.R. 371 (n. ${ }^{\circ} 99$, p. 407); STEDH MS v. Suecia, de 27 de agosto de 1997 (1999) 28 E.H.R.R. 313 (n. ${ }^{\circ} 41$, p. 338) libertad de intimidad"13. El concepto de datos personales, de manera genérica, se refiere al conjunto de informaciones de una persona física. Por lo cual la información que identifica a un individuo se vuelve parte integra de la persona humana, por lo cual su tratamiento sin el consentimiento del ciudadano deviene una violación a los derechos a la privacidad e intimidad conforme a las normas actuales en materia de protección de datos.

En América Latina, la protección de los datos se encuentra íntimamente vinculada al concepto de hábeas data - fenómeno que no es compartido en el contexto europeo o anglosajón. En el caso hondureño, la Constitución Política de 1982 en su artículo 182 reconoce la garantía de Hábeas Data, como el derecho que tiene toda persona de acceder a la información sobre sí misma o sus bienes en forma expedita y no onerosa, ya esté contenida en base de datos, registros públicos o privados y, en el caso de que fuere necesario, actualizarla, rectificarla y/o suprimirla.

El concepto de protección de datos, como tal, no está incluido en el derecho vigente en Honduras, si está en la Ley de Transparencia y Acceso a la Información Publica en el artículo tenemos los datos personales confidenciales: Los relativos al origen étnico o racial, características físicas, morales o emocionales, domicilio particular, número telefónico particular, dirección electrónica particular, participación, afiliación a una organización política, ideología política, creencias religiosas o filosóficas, estados de salud, físicos o mentales, el patrimonio personal o familiar y cualquier otro relativo al honor, la intimidad personal, familiar o la propia imagen. Cabe mencionar que la normativa hondureña no hace una diferencia entre la privacidad y la intimidad, lo que deja al sujeto de derecho en una exposición que atenta contra su imagen y dignidad.

Dentro de la normativa europea encontramos el concepto de dato personal en la Directiva $95 / 46^{14}$, en la cual se define como toda información sobre una persona física identificada 0 identificable; se considera identificable toda persona cuya identidad pueda determinarse, directa o indirectamente, en particular mediante un número de identificación 0 uno o varios elementos específicos, característicos de su identidad física, fisiológica, psíquica, económica, cultural o social. De manera menos detallada está la normativa española; en la Ley Orgánica 15/1999, de 13 de diciembre, de Protección de Datos de Carácter Personal se define como

13- Directiva 95/46/CE del Parlamento Europeo y del Consejo, de 24 de octubre de 1995, relativa a la protección de las personas físicas en lo que respecta al tratamiento de datos personales y a la libre circulación de estos datos

14- Directiva 95/46/CE del Parlamento Europeo y del Consejo, de 24 de octubre de 1995, relativa a la protección de las personas físicas en lo que respecta al tratamiento de datos personales y a la libre circulación de estos datos 
cualquier información concerniente a personas físicas identificadas o identificables. La redacción del artículo 25 de la Directiva 95/46/CE es bastante clara cuando tomamos en consideración que trata de explicar lo que se debe considerar un dato que efectivamente identifica a una persona.

Por otra parte, el concepto que da la Agencia Española de Protección de Datos ${ }^{15}$ es la capacidad que tiene el ciudadano para disponer y decidir sobre todas las informaciones que se refieran a él. Es un derecho reconocido en la Constitución Española y el Derecho Europeo y protegido por la Ley Orgánica de Protección de Datos (LOPD).

En el caso del correo electrónico la Agencia de Protección de Datos $^{16}$ lo considera como dato personal donde manifiestan que forman un conjunto de signos o palabras libremente elegidos generalmente por su titular con la única limitación de que dicha dirección no coincida con la correspondiente a otra persona, pudiendo con los datos obtenidos a través de una cuenta de correo, elaborar un perfil detallado del usuario quedando vulnerado con ello su intimidad y su vida privada. Por tanto, no importa si el correo no tiene vinculación directa hacia su usuario como en caso de un correo con un código (1009896524@ yahoo.es), ya que siempre estará relacionado a su usuario, mismo que siempre quedará debidamente identificado.

\section{Doctrina del Habeas Data.}

Una figura más, que es necesario nombrar cuando se hace referencia a la protección de los datos personales, es la del Habeas Data, la cual tiene más tiempo de existencia como tal, y que a decir de los doctrinarios especializados en el tema, coexiste con el de protección de datos personales, llegándose a tal punto de ser casi sinónimos, ya que se considera en un sentido general, que en esencia protegen lo mismo, con la única salvedad de que esta última es más concebida como un procedimiento, una acción, a la cual se puede acceder todo ciudadano en aras de que le sean cumplidos sus derechos constitucionales sobre protección de su persona.

\section{Jurisprudencia Europea.}

Bajo este mismo enfoque encontramos una sentencia en relación al derecho de intimidad misma que es congruente con los conceptos de dicha garantía constitucional que ya fueron descritos. Dicha sentencia ${ }^{17}$ fue emitida por el Tribunal

\footnotetext{
15- El Derecho Fundamental de Protección de Datos: Guía para el Ciudadano pág. 5 accesible en http://www.agpd.es/portalwebAGPD/canaldocumentacion/publicaciones/common/Guias/GUIA_CIUDADANO_OK.pdf

16- GUILLÉN CATALÁN RAQUEL, SPAM y comunicaciones Comerciales ...p 66

17- Google Spain SL, Google Inc. Agencia Española de Protección de Datos, Mario Costeja González, C-131/12 ECLI:EU:C:2014:317 Accesible en ingles en: http://eur-lex.europa.eu/legal-content/EN/
}

de Justicia de la Unión Europea, en la cual un ciudadano español, el señor Mario Costeja González demanda a Google Inc. por medio de su sede en España la cual es Google Spain. Dicho casó se elevó hasta el Tribunal de Justicia de la Unión Europea en virtud de una resolución de la Agencia Española de Protección de Datos en la cual se estimó una reclamación presentada por el señor Costeja González en su condición de afectado.

Dicha reclamación de fecha 5 de marzo de 2010, describía en sus hechos que cuando un internauta introducía el nombre del señor Costeja en el motor de búsqueda de Google, obtenía como resultado, varios vínculos hacia dos páginas del periódico La Vanguardia, del 19 de enero y del 09 de marzo de 1998 respectivamente, en las que figuraba un anuncio de una subasta de inmuebles relacionada con un embargo por deudas a la Seguridad Social, que mencionaba el nombre del señor Costeja González. En la petición solicitó que se exigiese a La Vanguardia eliminar o modificar la publicidad para que no apareciesen sus datos personales y que se exigiese a Google Spain (en concreto a Google Inc.) que se eliminaran u ocultasen sus datos personales para que dejaran de incluirse en sus resultados de búsqueda y que quedaran fuera de los enlaces del periódico La Vanguardia.

En la resolución de fecha 30 de julio de 2010 de primera instancia se estima parcialmente la reclamación en tanto que desestimó la medida contra el diario La Vanguardia, al considerar que la publicación que realizó dicho diario, estaba legalmente justificada, en virtud que fue realizada bajo orden del Ministerio del Trabajo y Asuntos Sociales español y tenía como finalidad dar la debida publicidad a la subasta para conseguir la mayor cantidad de licitadores. Por otro lado, se estimó la reclamación contra Google ya que la AEDP consideró que quienes gestionan motores de búsqueda llevan un tratamiento de datos del que son responsables, por lo cual estaba debidamente facultada para ordenar la retirada de la información personal de los motores de búsqueda en el supuesto de que su localización y difusión puede lesionar el derecho fundamental a la protección de datos y a la dignidad de la persona.

Google interpuso Recurso de Apelación contra dicha resolución, ante la Audiencia Nacional, en la cual ordena suspender la misma, en virtud de remitir la causa al Tribunal Constitucional a fin de que se pronuncie en relación con ciertas interrogantes que fueron presentadas. El debate se centra en el hecho en que Google presenta como argumento principal, que la actividad de los motores de búsqueda no debería considerarse tratamiento de los datos que se muestran en su página perteneciente a terceros.

ALL/?uri=CELEX:62012CJ0131 o en castellano en: http://curia.europa.eu/ juris/document/document.jsf?text $=\&$ docid $=152065 \&$ pagelndex $=0 \&$ doclang $=E S \&$ mode $=I s t \& d i r=\& o c c=$ first $\&$ part $=1 \&$ cid $=213683$

Revista de Derecho. Vol. 37, No. 1, Año 2016|-69 
Mientras que la contraparte manifiesta que el gestor de un buscador es responsable del tratamiento de datos efectuado por él, desde el momento en que se determina la finalidad y los medios de dicha acción, y en el presente caso se determina que Google en su actividad recoge, extrae, registra y organiza los datos que maneja; además de que eventualmente los conserva en sus servidores.

Concluyendo el Tribunal de Justicia de la Unión Europea que "la manipulación lícita de datos, inicialmente, puede devenir incompatible con la Directiva 95/46/CE cuando estos datos ya no sean necesarios, en relación con los fines recolectados o trataron". Por otra parte, considera "que teniendo en cuenta el carácter sensible de la información contenida en dichos anuncios para la vida privada de esta persona (el afectado,) además que su publicación inicial se remonta a 16 años atrás, el interesado justifica que tiene derecho a que esta información ya no se vincule a su nombre". Por lo cual se condenó en costas a Google inc. y Google Spain; además se decretó la orden de eliminar de los datos relativos al señor Mario Costeja González.

\section{Tratamiento de datos personales de los aspirantes a magistrados de la CSJ.}

Tomando en consideración el caso en específico, el proceso de selección de candidatos a magistrados de la CSJ recién pasado, en el que se evidenció el importante papel que desempeñaron los miembros de la Junta Nominadora, en su condición de responsables del tratamiento de datos, los comisionados del Instituto de Acceso a la Información Pública (IAIP), representantes de los medios de comunicación y miembros de Sociedad Civil entre otros actores.

Dicha Junta Nominadora fue creada con el objetivo de elaborar una propuesta de candidatos para la elección de Magistrados de la Corte Suprema de Justicia.

Para dar cumplimiento a dicho mandato, la JN procede a emitir su primera resolución en la cual aprueban la normativa pertinente, la cual fue aprobada por todos los miembros, en fecha diecisiete de septiembre del año dos mil quince, siendo publicada en el Diario Oficial La Gaceta en fecha veinticinco de septiembre de dos mil quince, No. 33,843.

Posteriormente, la JN procede a emitir la respectiva convocatoria, en la que están los comprendidos los datos personales confidenciales definidos así, por la LTAIP en el artículo 3 inciso 7); la cual fue publicada el día lunes 14 de septiembre, 2015, en el Diario La Tribuna, la cual dice: "En cumplimiento de los artículos 311 de la Constitución de la Republica, 17 y 18 de la Ley Orgánica de la Junta Nominadora para la Elección de Candidatos a Magistrados de la Corte Suprema de Justicia, contenido en el Decreto No. 140-2001, por medio de la presente CONVOCA ${ }^{18}$

Adicional a los requisitos establecidos en la $\mathrm{CRH}$, solicitaron una autorización firmada por los aspirantes para que los miembros de la JN tuvieran acceso a todos la información pertinente al proceso, también deberían firmar la carta de reconocimiento de que el proceso de selección ante la Junta Nominadora es un Concurso Público; vale hacer la aclaración que ambas notas autorizan a la JN para una función específica, pero no le facultan a la JN ni a otra institución pública o privada a publicar sus datos personales, en ningún momento se puede entender una aceptación tácita para la divulgación de su información personal.

Inicialmente la JN mediante resolución de fecha veintinueve días del mes de septiembre del año dos mil quince ${ }^{19}$, en el punto número 2. Literalmente resuelve: "Publicar solamente las resoluciones de la Junta Nominadora en los portales respectivos." Con el propósito de que no se publique más información de la necesaria, y así evitar el riesgo de exponer la información personal de los aspirantes.

Y en el Acta de fecha veintidós de septiembre de dos mil quince $^{20}$; en punto de acta número 1. Resuelve: Practicar las pruebas de confianza a todos los aspirantes a Magistrados de la Corte Suprema de Justicia: Poligráfica, Toxicológica, Psicológica y socioeconómica, a través de la Dirección Nacional Investigación e Inteligencia por ser el órgano legal; 2. Solicitar a cada aspirante una copia fotostática de sus documentos para la práctica de las pruebas de confianza, y se fundamentó en la Ley General de la Superintendencia para Aplicación de Pruebas de Evaluación de Confianza en el artículo número 5 que dice: "AMBITO DE APLICACIÓN. La presente Ley será aplicable a funcionarios de alto nivel del gobierno, a candidatos a magistrados del Poder Judicial..."

Posteriormente, el IAIP en su Resolución No. SE-002$2015^{21}$ en el cuarto punto dice "Los miembros de la JUNTA NOMINADORA PARA LA ELECCIÓN DE CANDIDATOS A MAGISTRADOS DE LA CORTE SUPREMA DE JUSTICIA así como los candidatos al cargo de Magistrados a la CORTE SUPREMA DE JUSTICIA, deben brindar su autorización para el acceso y difusión de sus datos personales a efecto de

18- Convocatoria Junta Nominadora para la Elección de Candidatos a Magistrados de la Corte Suprema de Justicia, Diario La Tribuna, Lunes 14 de septiembre 2015.

19- Acta sesión de Junta Nominadora de fecha 29 de septiembre de 2015.

20- Acta sesión de Junta Nominadora de fecha 22 de septiembre de 2015.

21- Resolución No. SE-002-2015 de fecha 9 de septiembre de 2015 correspondiente al expediente no. 007-2015-IO del Instituto de Acceso a la Información Pública. 
"El Derecho fundamental de protección de datos personales de los aspirantes a Magistrados de La Corte Suprema de Justicia de Honduras, proceso de selección 2015 - 2016"

acreditar, ante el pueblo hondureño, que reúnen los requisitos legales y éticos para el desempeño del cargo."

Sin embargo, en la Certificación de Resolución No. SE-0032015 de fecha quince (15) de octubre de dos mil quince (2015) se expone en su parte resolutiva que se procede a amonestar por escrito a los miembros, propietarios y suplentes de la JN para la elección de candidatos de la CSJ por haber incumplido, en forma expresa a lo ordenado en la Resolución No. SE-002-2015 y el artículo 3 del Decreto No. 140-2001 que contiene la Ley Orgánica de la JN.

Asimismo, el IAIP nuevamente mediante Resolución No. SE-004-2015 de fecha veintitrés (23) de octubre de dos mil quince (2015), resuelve, ordenar a la JUNTA NOMINADORA PARA LA ELECCION DE CANDIDATOS MAGISTRADOS DE LA CORTE SUPREMA DE JUSTICIA, publicar los resultados de las pruebas de confianza realizadas a los candidatos a ocupar el cargo de MAGISTRADOS DE LA CORTE SUPREMA DE JUSTICIA, para lo cual se deberán elaborar las correspondientes versiones públicas, en las cuales se determinara si la servidora o servidor público aspirantes en general aprobó o reprobó las pruebas que le hayan sido realizadas, sin publicar detalles que se refieran a su estado de salud físico o mental.

Y en respuesta la JN interpuso Recurso de Reposición en contra de la Resolución SE-004-2015 a través de su presidente Ricardo Rodríguez. Entre los agravios se menciona que la publicación de los resultados de las pruebas de confianza aplicadas a cualquier persona vulnera sus derechos humanos conforme a las apreciaciones siguientes: El articulo 3 numeral 7) de la Ley de Transparencia señala Los datos personales confidenciales, "son los relativos al origen étnico o racial, características físicas morales o emocionales, domicilio particular, número telefónico particular, dirección electrónica particular, participación, afiliación a una organización política, ideología política, creencias religiosas o filosóficas, estados de salud, físicas o mentales, el patrimonio personal o familiar y cualquier otro relativo al honor, la intimidad personal, familiar o la propia imagen."

\section{Conclusiones}

Dada la importancia del ser humano para la sociedad y el Estado $^{22}$ según la Constitución de la Republica, el presente estudio se ha focalizado en el derecho fundamental de la protección de datos personales derivados del derecho al honor, la intimidad y la privacidad de los aspirantes a magistrados de la CSJ de Honduras, periodo 2016 - 2023. Tomando como fundamento el artículo numero 76 Constitucional, que en su texto estipula: "Se garantiza el derecho al honor, a la intimidad

22- Articulo 57 Constitución de la Republica de 1982. personal, familiar y a la propia imagen." Cabe aclarar que la protección de datos no es instrumento de opacidad en el proceso. Del presente análisis se concluye:

\section{Del conocimiento y delimitación normativa de la protección de datos.}

\section{a) Concepto de tratamiento de datos conforme a la jurispru-} dencia analizada.

El concepto de tratamiento de datos es bastante amplio conforme a la doctrina y a la jurisprudencia analizada, tomando el ejemplo de la sentencia del señor Costeja contra Google España, donde dicha empresa manifestaba que ellos no hacían un tratamiento de datos propiamente dicho; sin embargo, el tribunal fue tajante al determinar que: la puesta a disposición de páginas de internet para los usuarios del buscador representaba un tratamiento de datos desde el punto de vista jurídico.

En Honduras, la mayor controversia relacionada con el tema estudiado, surgió del proceso de selección de los candidatos a magistrados de la CSJ periodo 2016 - 2023.

\section{b) El Habeas Data y la Protección de datos personales.}

Del conocimiento de la normativa nacional e internacional, doctrina y jurisprudencia relacionada; se afirma que el Habeas Data y el Derecho fundamental de protección de datos, no son la misma figura, el Habeas Data se encuentra regulado a través de la norma adjetiva, siendo en el caso de Honduras la Ley Sobre Justicia Constitucional, y la protección de datos es regulada por la norma sustantiva tanto en la legislación nacional como en el ámbito internacional. Este derecho tiene sus fundamentos en el derecho de privacidad e intimidad y con cierta influencia sobre el derecho al honor.

\section{c) Del consentimiento escrito de los aspirantes.}

Los aspirantes a altos cargos del Estado, expresan su consentimiento para que una autoridad legitimada pueda realizar un tratamiento de sus datos personales y las investigaciones pertinentes al proceso que tiene como objetivo aprobar o improbar la idoneidad, imparcialidad y capacidad para desempeñar un cargo. Sin embargo, dicha manifestación de consentimiento, no se debe considerar o interpretar como una autorización del afectado para publicar sus datos personales bajo ningún medio de comunicación, entre ellas las redes sociales.

d) De la naturaleza de los Derechos al honor, la intimidad, privacidad y acceso a la información pública. 
La confusión en la naturaleza de los derechos al honor, la intimidad, la privacidad y el derecho al acceso de la información pública, facilitan la vulneración al derecho fundamental de la protección de datos personales de los aspirantes a magistrados en el proceso de selección 2015 - 2016 y demás aspirantes a altos cargos del Estado en Honduras.

\section{e) De la naturaleza jurídica de las pruebas de confianza.}

Se deduce que ninguna de las pruebas den confianza podía ser entregada a terceros, y mucho menos publicadas, por estar clasificadas como confidenciales, por la Ley General de la Superintendencia para la aplicación de Pruebas de Evaluación de Confianza y dada la preeminencia de la misma Ley. Se debe tener presente, que toda persona tiene derecho de accesar a la información pública que no sea considerada confidencial o reservada, sin que esto conlleve a la opacidad del proceso.

\section{Acciones ejecutadas por los órganos com- petentes en el tratamiento de datos persona- les de los aspirantes.}

a) De las encuestas relativas al tratamiento ejecutado por la JN.

Del análisis de las encuestas practicadas, se concluye que un $80 \%$ de los encuestados considera que efectivamente la $\mathrm{JN}$ en su condición de responsable del tratamiento de datos de los aspirantes a magistrados de la CSJ, realizó un tratamiento de datos parcialmente adecuado. Si bien es cierto la JN como tal, no publicó los datos personales de los aspirantes, también es cierto que los mismos fueron publicados parcialmente por terceros.

Cabe resaltar que en su actuar público, la JN cumplió con los principios doctrinales relativos al tratamiento de datos, aunque con ello haya incumplido la resolución No. SO-0022016 del IAIP, bajo la preeminencia que antepone el derecho al honor del ser humano en relación al derecho a la información pública.

b) De las encuestas relativas al tratamiento ejecutado por otros órganos estatales.

Del análisis de las encuestas practicadas se deduce que un $70 \%$ de los encuestados considera que estos órganos, en su condición de garantes del Estado en materia de protección de datos personales, no actuaron adecuadamente, ya que en todo momento denotaron una clara confusión entre el bien jurídico protegido (ser humano) y el derecho de acceso a la información pública (en función de un interés particular).

\section{Vacíos jurídicos del tratamiento de datos personales en Honduras.}

a) Del análisis la normativa vigente en Honduras.

Se deduce que la misma no presenta una regulación adecuada para el tratamiento de datos personales como derecho fundamental; careciendo de una definición de dicha actividad, y muchos otros aspectos relacionados; permitiendo excesos, basados en el principio de la transparencia y acceso a la información pública., debido a que en la actualidad se encuentra un tanto escueta la normativa en la materia.

b) Análisis de la Ley de Transparencia y Acceso a la Información Pública.

Esta Ley tiene como finalidad desarrollar y ejecutar la política nacional de transparencia, y al acceso a la información pública para el fortalecimiento del Estado de Derecho y consolidación de la democracia mediante la participación ciudadana; no así, la función específica de la protección de datos personales, como derecho fundamental y sus consecuencias, ya que no lo regula de manera directa. En este caso resulta necesario crear la Ley de Protección de Datos Personales Hondureña.

\section{Del tratamiento de datos de los aspirantes.}

Del análisis de la normativa nacional e internacional, doctrina, jurisprudencia, y las encuestas realizadas se deduce que los datos personales de los aspirantes a magistrados del recién pasado proceso de selección no fueron protegidos adecuadamente, facilitando de manera indirecta los daños al honor y a la imagen de los aspirantes.

\section{Aporte de la investigación}

Concepto de tratamiento de datos personales en base al análisis realizado.

Cualquier acción conducente a la injerencia manual o automatizada de datos de una persona natural, requiere, del consentimiento expreso, preciso e inequívoco de su finalidad, de fines legitimados, afines a los principios de respeto al honor, intimidad, privacidad, responsabilidad, proporcionalidad, protección, transparencia, y buena fe, salvo en los casos ordenados por un juez competente. 


\section{Bibliografia}

1. De Jure. Instituto Universitario De Just. Universidad De Colima. Año 5. Segunda Época. Numero 3. Colima, México. Septiembre 2005, páginas 62, 63 y 66.

2. Enciclopedia Jurídica Mexicana IV, F-L. Universidad Nacional Autónoma de México. Editorial Porrúa. Instituto de Investigaciones Jurídicas.

3. El Diccionario de la lengua española (DRAE) es la obra de referencia de la Academia. La última edición es la 23. a , publicada en octubre de 2014.

4. 4.El Derecho Fundamental de Protección de Datos: Guía para el Ciudadano pág. 5 accesible en http://www. agpd.es/portalwebAGPD/canaldocumentacion/publicaciones/common/Guias/GUIA_CIUDADANO_OK. pdf

5. http://eur-lex.europa.eu/summary/glossary/information society.html?locale=es

6. Principios Rectores para la Reglamentación de los Ficheros Computadorizados de Datos Personales Adopción: Asamblea General de la ONU Resolución 45/95, 14 de diciembre de 1990.

\section{Artículos Doctrinales}

7. GUILLÉN CATALÁN, Raquel: "SPAM y comunicaciones Comerciales no solicitadas", en Revista Aranzadi de derecho y nuevas tecnologías, Editorial Aranzadi 2005 , p. 35 en referencia a la sentencia de 20 de julio de 1993.

8. GOZAíNI, OSVALDO ALFREDO, Derecho Procesal Constitucional Hábeas data Protección de Datos Personales, Argentina, Editorial Rubizabal-Culzoni Editores. Pág. 113 y 114

9. TREJO DELARBRE, RAUL (2001) Vivir en la Sociedad de la Información; Orden global y dimensiones locales en el universo digital, Revista Iberoamericana de Ciencia y Tecnología, Sociedad e Innovación, Número 1 / Septiembre - diciembre 2001.

10. VANOVER R. (2011) Five benefits of linkedin for organizations (and it pros) | techrepublic.com." may 9.
Jurisprudencia:

11. Google Spain SL, Google Inc. Agencia Española de Protección de Datos, Mario Costeja González, C-131/12 ECLI:EU:C:2014:317 Accesible en ingles en: http://eur-lex.europa.eu/legal-content/EN/ ALL/?uri=CELEX:62012CJ0131 o en castellano en: http://curia.europa.eu/juris/document/document.jsf?text $=\&$ docid $=152065$ \&pagelndex $=0 \&$ doclang $=E S \&$ mode $=1$ st\&dir=\&occ=first\&part=1\&cid=213683.

\section{Directivas de la Unión Europea}

12. Directiva 95/46/CE el Parlamento Europeo y del Consejo, de 24 de octubre de 1995, relativa a la protección de las personas físicas en lo que respecta al tratamiento de datos personales y a la libre circulación de estos datos.

\section{Tratados Internacionales}

13. Declaración Universal de los Derechos Humanos del 10 de diciembre de 1948 en Francia accesible en http:// www.humanium.org/es/ddhh-texto-completo/\#

14. Pacto de Derechos Civiles y Políticos Adoptado y abierto a la firma, ratificación y adhesión por la Asamblea General en su Resolución 2200 A (XXI), de 16 de diciembre de 1966 Entrada en vigor: 23 de marzo de 1976, de conformidad con el artículo 49 accesible en: http://www.acnur.org/t3/fileadmin/scripts/doc. php?file=t3/fileadmin/Documentos/BDL/2001/0015

15. Convención Americana Sobre Derechos Humanos (Pacto de San José) San José, Costa Rica 7 al 22 de noviembre de 1969 Artículo 11. Protección de la Honra y de la Dignidad. Accesible en: http://www.oas.org/dil/ esp/tratados_b-32_convencion_americana_sobre_derechos_humanos.htm

\section{Normativa Nacional}

16. Constitución de la Republica de Honduras de 1982

17. 17. Decreto $\mathrm{N}^{\circ}$ 170-2066 Ley de Transparencia y Acceso de la Información Pública IAIP-HONDURAS. 
18. Decreto No. 244-2003 Ley sobre justicia Constitucional; publicada en el Diario Oficial La Gaceta No. 30,792 de fecha 03 de septiembre de 2005.

19. Decreto N ${ }^{\circ} 254-2013$ Ley General de la Superintendencia para la aplicación de Pruebas de Evaluación de Confianza; publicada en el Diario Oficial La Gaceta No.33,372 de fecha 06 de marzo de 2014.

20. Decreto No. 140-2001 Ley Orgánica de la Junta Nominadora para la elección de candidatos a Magistrados de la Corte Suprema de Justicia de fecha 01 de octubre de 2001; publicada en el Diario Oficial La Gaceta No. de fecha 05 de octubre de 2001.

\section{Normativa Internacional}

21. Artículo 18 Constitución del Reino de España

Resoluciones hondureñas:

22. Resolución No. 01-2015-JN. Normativa de la Junta Nominadora para la Elección de Candidatos a la Corte Suprema de Justicia Periodo 2015 - 2016. en el Diario Oficial La Gaceta en fecha veinticinco de septiembre de dos mil quince, No. 33,843.

23. Acta sesión de Junta Nominadora de fecha 22 y 29 de septiembre de 2015.

24. Resolución No. SE-002-2015 de fecha 9 de septiembre de 2015 correspondiente al expediente no. 007-2015-IO del Instituto de Acceso a la Información Pública. 